\title{
Fernanda Costa - Retrato
}

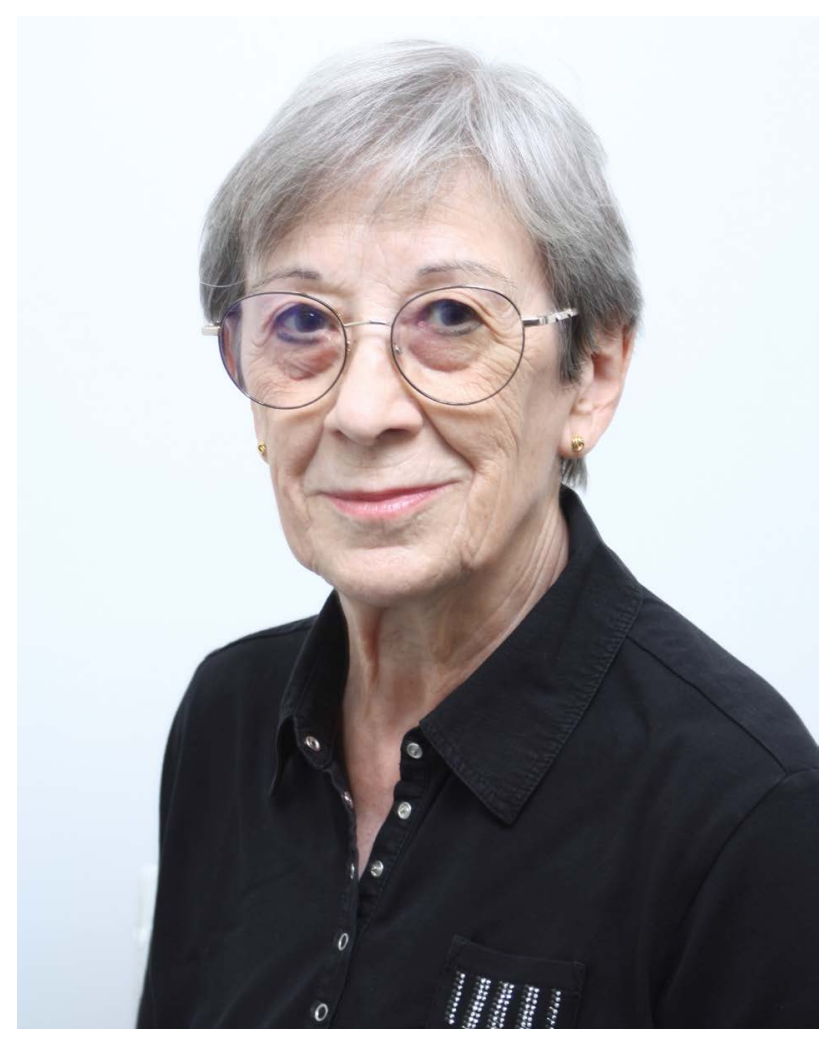

Fernanda Costa é Professora Catedrática Jubilada da Faculdade de Ciências da Universidade de Lisboa. Foi Investigadora no Centro de Radioquímica e no Centro de Ciências Moleculares e Materiais. Publicou mais de $\mathbf{9 0}$ artigos em revistas nacionais e internacionais. Foi diretora do Museu Nacional de História Natural e da Ciência da Universidade de Lisboa de 2003 a 2006. É autora do livro " 100 Anos de Fotografia Científica em Portugal 1839-1939: imagens e instrumentos".
$>$

Interação Química com

Maria José Lourenço Fernanda Costa

mjlourenco@ciencias.ulisboa.pt fernanda.madalena@sapo.pt
O retrato desta secção apresenta-nos uma mulher jovial, dinâmica, corajosa, sem receios para a investigação e com a capacidade de contagiar e entusiasmar quem a rodeia. Estimulada por mistérios por resolver, técnicas de caracterização pouco conhecidas, desafios tecnológicos, facilmente aceitou partilhar a sua vida de cientista por videoconferência. Ficámos a conhecer a enorme importância de 100 anos de fotografia científica em Portugal e como os museus do nosso país guardam verdadeiros tesouros químicos, alguns ainda por explorar. 0 acesso a arquivos digitais em todo o mundo deu a perceber que a herança recebida dos nossos mais antigos professores portugueses de química representa uma imensa riqueza científica e tecnológica já implementada ao serviço da sociedade ao longo de vários anos. Estamos orgulhosos da investigação química que realizamos em Portugal há mais de um século.

Como caracteriza os seus primeiros anos? Nasci em Lisboa, em 1944, na freguesia de São Sebastião da Pedreira. Sou filha única, frequentei o liceu Rainha Dona Leonor, instalado em parte do Palacete da Ribeira Grande, situado na Rua da Junqueira. A frequência desta escola era exclusivamente feminina.

\section{E como se inclinou para a Química?}

Fui muito influenciada pela minha professora de Físico-Químicas e pela professora Julieta de Biologia com as suas ideias muito fortes de interação com as ciências. Nesta altura já tinha uma grande paixão pela investigaç̧ão, principalmente pelos trabalhos práticos. Mas quero salientar que a minha madrinha, muito mais velha e com um curso de preparadora foi quem mais me persuadiu. Lina Libânia Pinto Barreto, nasceu em 1902, solteira, professora de instrução primária, tinha um curso de piano e violino pelo conservatório além de ser preparadora de laboratório. Se pensarmos que tudo isto aconteceu há 100 anos! 


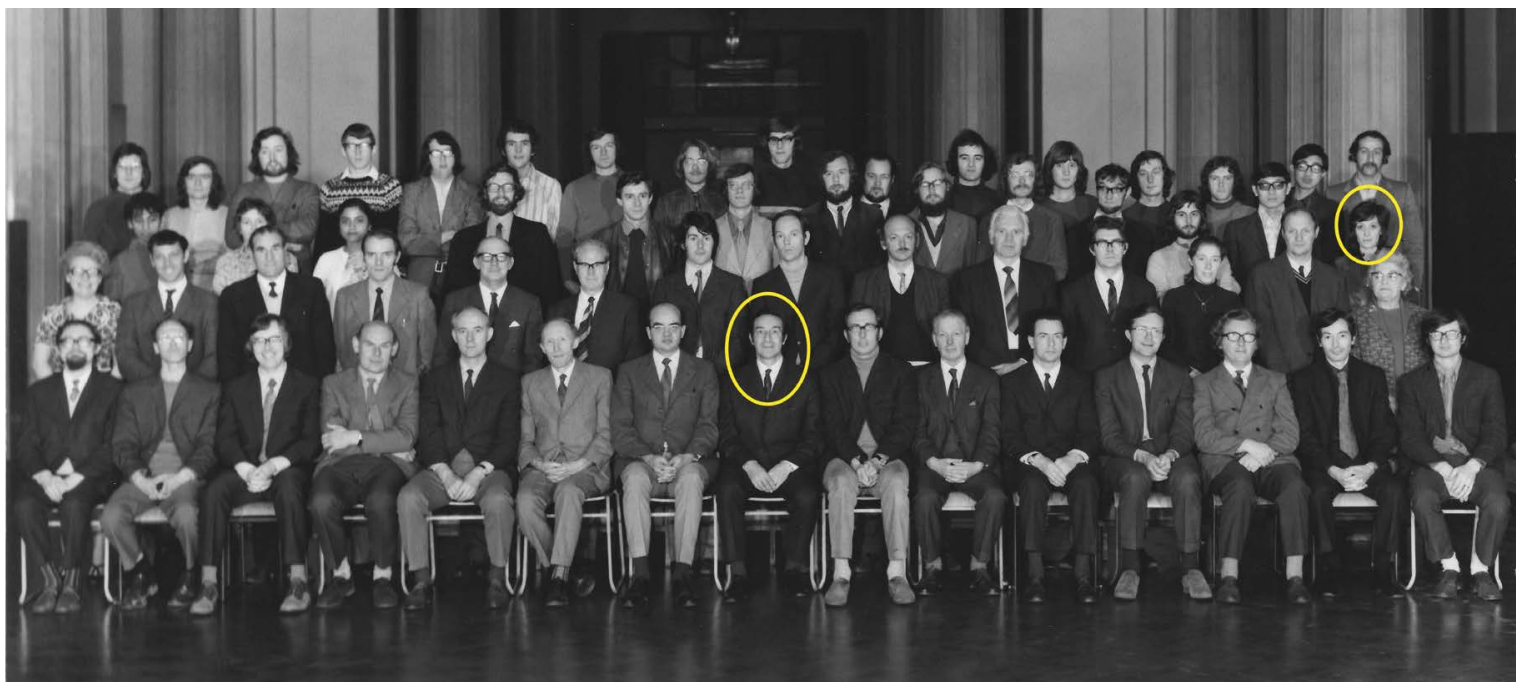

Leeds, Inorganic Structural Chemistry Department, 1975; a imagem representa o grupo correspondente ao Departamento de Química Inorgânica e Estrutural da Universidade de Leeds; na primeira fila sentavam-se os professores, com o Professor Greenwood (diretor) em destaque na parte central; na segunda fila, de pé, os técnicos e funcionários administrativos; na terceira e quarta filas os assistentes de investigação e alunos de pós graduação à frente e os alunos de mestrado e doutoramento (Fernanda Costa em destaque) um pouco mais atrás (registo fotográfico anual).

\section{Como foi a sua entrada na Universidade?}

Foi fácil. Estava decidida, tinha as minhas ideias e a família dava-me total liberdade para fazer o que mais gostasse. Estou muito grata por tudo isto que considero fundamental na vida. Tinha 18 anos, entrei para o curso de Físico-Químicas de quatro anos, usufruindo durante esse período de uma bolsa da Fundação Calouste Gulbenkian.

\section{O que destaca no seu curso?}

Alguns professores que me marcaram, colegas e amigos para sempre, e mais tarde, já a realizar o meu doutoramento em Leeds constatei que as aulas de Física e de Cristalografia se tinham tornado fundamentais para desenvolver o trabalho da tese. Destaco três professores: Marieta da Silveira e Pinto Peixoto (tem uma estátua de bronze no Campo Grande, frente à Faculdade de Ciências) pela forma de raciocinar, pela metodologia única para pensar globalmente e a Professora Branca Edmée Marques pela forte componente da investigaç̧ão.

\section{Quais as disciplinas que mais gostava?}

Todas as de Química. Afirmava e confirmo que a Química é a ciência responsável pelas propriedades que se observam e se medem na Física.

\section{Para além da vida académica que outras atividades lhe agradavam?}

Já tinha grande interesse por museus, pintura, artesanato e realizava vários trabalhos manuais que continuo a gostar muito de fazer.

\section{E quando terminou a Universidade o que aconteceu?}

Fui dar aulas de Físico-Química para o Liceu Maria Amália e de Matemática (em regime noturno) para a Escola Secundária do Cacém... Mas o que eu queria mesmo era fazer investigação e comecei a trabalhar com a Professora Branca no Laboratório de Radioquímica que viria a dar origem ao Centro de Estudos de Radioquímica da Comissão de Estudos de Energia Nuclear, primeiro centro de investigação em Química da Faculdade de Ciências da Universidade de Lisboa, situado na Rua da Escola Politécnica, em Lisboa. Entretanto concorri a assistente na Faculdade de Ciências da Universidade de Lisboa e aí segui a carreira académica.

O meu primeiro trabalho, juntamente com Maria Regina Grade e a Professora Branca intitulava-se Limite de detection du calcium par photometrie de flame. Este trabalho data de 1971 e foi publicado num Special Issue do $3^{\text {rd }}$ International Congress of Atomic Absortion and Atomic Fluorescence Spectrometry [1]. Por esta altura já trabalhava no laboratório o Manuel Rosa Nunes que viria a ser um dos meus doutorandos. O Manuel sabia quase tudo o que se passava por ali e com ele percebi a importância estratégica do laboratório de radioquímica. Por exemplo, a partir de 1961 controlava-se o ar atmosférico devido aos ensaios nucleares franceses no Saara argelino; em colaboração com a Marinha portuguesa, eram frequentes os ensaios de monitorização das águas do Tejo, que se mostraram muito úteis logo a seguir ao 25 de abril de 1974 devido à paragem de submarinos americanos na Trafaria. Aconteceu por este ano que em laboratórios internacionais (por exemplo na 
Alemanha) tinha sido detetado em amostras de Vinho do Porto álcool com valores anormalmente baixos de carbono-14. Estes dados sugeriam que o álcool não tinha resultado unicamente da fermentação de uvas e posterior destilação, mas que tinha sido produzido por síntese química a partir de materiais fósseis. As cooperativas vinícolas do Douro pediram a realização de várias análises ao laboratório de radioquímica e, com a interferência do Laboratório de Física e Engenharia Nucleares situado em Sacavém, foi possível perceber o sucedido e que em nada prejudicava a saúde. Mas o Manuel é a pessoa indicada para nos contar muitos destes episódios. Ele tem uma excelente memória!

\section{Como aconteceu o seu Doutoramento?}

Continuei a trabalhar com a Professora Branca. Gostava muito de espectroscopia. Um dia a Professora, já jubilada, falou-me numa nova espectroscopia denominada de Mössbauer que lhe interessava muito e que utilizava uma fonte de radiação gama. Perguntou-me se eu estava interessada neste estudo, a realizar fora do país, e explicou-me com entusiasmo que a técnica era desafiante também por ser muito recente. Não hesitei em aceitar o trabalho. Estava decidida a fazer o meu doutoramento em Inglaterra.

Nessa data fiz um acordo com o meu marido que consistia no compromisso de casarmos, mas com a garantia de fazer o doutoramento em Leeds. Ele tinha muito interesse em estudar engenharia automóvel e conciliou a sua atividade para me acompanhar em Inglaterra. Era necessário pedir financiamento para esta aventura, o que se concretizou com a atribuição de uma bolsa pela Comissão Permanente INVOTAN que flexibilizava a data de início dos trabalhos. Existia uma grande incerteza para a data de início dos trabalhos, pois o meu orientador em Leeds, Norman Neil Greenwood, estava de mudanças da Universidade de Newcastle-upon-Tyne para inaugurar e chefiar o Department of Inorganic and Structural Chemistry. Permaneci em Lisboa durante o ano 1971/72 no meu trabalho de assistente e mergulhada no estudo bibliográfico da radiação gama. Mas, entretanto, engravidei e nasceu a minha filha. Com a chegada do Professor Greenwood a Leeds estavam finalmente criadas todas as condições para que a parte experimental do meu trabalho se iniciasse em setembro de 1972. Não é difícil imaginar que levei a família comigo, incluindo a minha mãe!

Frequentava várias disciplinas, estudava propriedades magnéticas e tinha muito trabalho no laboratório, em particular de síntese inorgânica de compostos, principalmente óxidos para estudo por espectroscopia Mössbauer e caracterização das propriedades elétricas e magnéticas. De salientar que sintetizei tricloreto de ruténio ultrapuro, fundamental para a caracterização Mössbauer do Ruténio-99 e todo o pessoal do laboratório, incluindo o Professor Greenwood, vibrou com os resultados obtidos.

$\mathrm{Na}$ minha tese demonstrei que podiam existir valências intermédias com tempo de vida estimável alterando as propriedades exibidas pelos materiais em função da ocupação iónica da estrutura cristalina.

\section{E como era a relação com a Professora Branca, discípula de Madame Curie?}

É bom realçar que não existia e-mail! Para além dos relatórios exigidos pela bolsa da INVOTAN enviava-Ihe relatórios para que fosse acompanhando o meu trabalho.

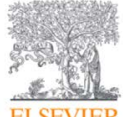

Chemical Physics Letters

volume 36, Issue 5, 15 December 1975, Pages 655-657

\section{The ${ }^{99} \mathrm{Ru}$ Mössbauer spectrum of $\beta-\mathrm{RuCl}_{3}$ \\ F.M. Dacosta, T.C. Gibb, R. Greatrex, N.N. Greenwood \\ Department of Inorganic and Structural Chemistry, The University, Leeds LS2 9JT, UK \\ Received 31 July 1975, Available online 24 October 2001. \\ Artigo resultante do trabalho de caracterização do Ruténio-99 por espectroscopia Mössbauer.} DOI: 10.1016/0009-2614(75)85360-7.

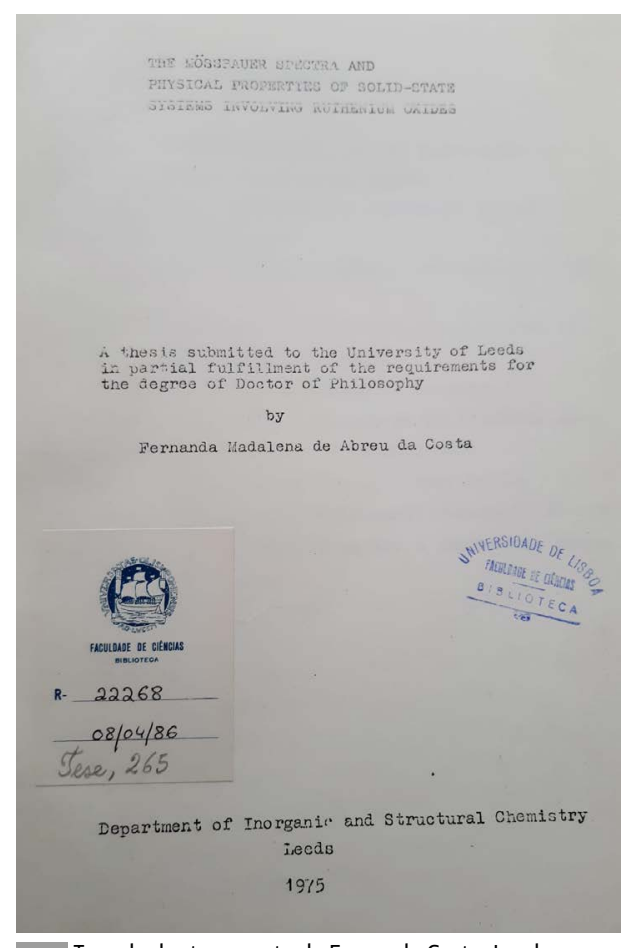

Tese de doutoramento de Fernanda Costa, Leeds, 1975 (cópia do original, tese n. $^{\circ} 265$, Biblioteca Central, Faculdade de Ciências da Universidade de Lisboa). 
Que atitudes e metodologias existiam no laboratório de Leeds em relação à segurança? No laboratório onde estavam os espectrómetros Mössbauer existiam fortes protocolos relativos à manipulação e armazenamento das diferentes fontes de radiação gama. Existiam inspeções periódicas da entidade reguladora oficial para controle da contaminação radioativa. A fonte para os meus compostos (metais/semicondutores da época) era de Ruténio-99, energeticamente alta, havendo necessidade de bastante cuidado nos ensaios.

Na sua tese The Mössbauer spectra and physical properties of solid state systems involving ruthenium oxides, a primeira referência bibliográfica que utiliza pertence a John Bannister Goodenough, atualmente com 99 anos e prémio Nobel da Química em 2019. Quer comentar este trabalho referido e datado de 1971 [2]?

Era um texto obrigatório que incluía trabalhos suportados pela indústria com lig̉ação aos semicondutores (considerados o advento da química dos materiais), explorava óxidos de metais de transição e eu estava decidida a "brincar" com estas estruturas. Esta referência é igualmente considerada precursora na área.

O seu orientador de doutoramento foi Norman Neill Greenwood. Juntamente com Terence Charles Gibb publicaram, em 1971, Mössbauer Spectroscopy, pela editora Chapman and Hall [3]. Quer comentar a importância deste livro e única referência do seu orientador para o trabalho que desenvolveu?

A técnica de Mössbauer, além de perigosa, também é dispendiosa e tem uma tabela periódica própria, sendo por isso pouco utilizada. É uma técnica muito útil no estudo dos materiais pois permite determinar a variação das interações eletrónicas, pelos estados e desdobramentos energéticos do núcleo, aplicável por exemplo na interpretação das propriedades físicas elétricas e magnéticas. Obtém-se uma grande versatilidade de propriedades quando se retira estequiometria aos óxidos e isto foi vantajoso no desenho de novos materiais. Terence Gibb era o químico que me ajudava e ensinava na interpretação dos espectros. Estes aspetos resumem uma grande parte do livro do meu orientador e a sua leitura atenta foi fundamental durante o meu doutoramento.

\footnotetext{
Alfred Gavin Maddock foi o seu arguente de doutoramento. Durante a Segunda Guerra Mundial Maddock trabalhou nos projetos "Tube Alloys" e "Manhattan" que deram origem ao desenvolvimento da bomba atómica. Lembra-se do dia do
}

seu doutoramento? Como foi o regresso a Portugal?

Lembro-me de ser em agosto, salvo erro no dia 8, pois o Professor Maddock foi o arguente designado para a discussão e a partir de setembro ia em sabática para os Estados Unidos. Tive de escrever a tese num apertado espaço de tempo e ir pessoalmente a Cambridge entregá-la. Eu tinha urgência em regressar a Lisboa. O financiamento há meses que estava suspenso devido à situação política do momento e aproximava-se o início de um novo ano letivo. A minha família já se encontrava em Portugal e assim consegui regressar em agosto de 1975, uns dias depois da defesa da tese.

Ao longo da sua carreira, Greenwood também atribuiu grande importância ao ensino e escreveu a grandiosa publicação Chemistry of the Elements, publicada pela primeira vez em 1984. Este livro tornou-se um dos textos em química inorgânica mais vendido em todo o mundo e foi traduzido para vários idiomas. Como descreve a sensação de recomendar o livro de autoria do seu supervisor aos seus alunos 10 anos depois de retomar a vida académica na Faculdade de Ciências da Universidade de Lisboa?

Foi um orgulho enorme recomendar os trabalhos do "meu" Professor e sentia que a divulgação do seu trabalho, de reconhecido valor, era um sentimento de gratidão pela excelência de formação e aprendizagem que me proporcionara.

\section{Como aconteceu a direção do Museu} Nacional de História Natural e da Ciência? No final de 2002 o Professor Virgílio Meira Soares contactou-me explicando que o Laboratório e Anfiteatro de Química do MUHNAC ia finalmente ser recuperado com um mecenato concedido pela Apifarma - Associação Portuguesa da Indústria Farmacêutica, mas que o Professor Bragança Gil, fundador e diretor do Museu, devido à idade, teria de ser substituído. Considerando o meu perfil e tratar-se de uma recuperação na área da Química, o Professor Virgílio propunha a minha nomeação para diretora de modo a coordenar e acompanhar os trabalhos que se iriam iniciar e que envolviam a limpeza prévia dos espaços ocupados com material e reagentes antigos. Fiquei surpreendida e hesitei pensando nas aulas e projetos de investigaçãa em curso; mas o desafio da recuperação daqueles espaços que tanto me diziam, levaram a que acabasse por aceitar.

É indiscutível a sua ligação e coordenação da recuperação do Laboratorio Chimico 


\section{da Politécnica. O seu nome ficará sempre associado a este espaço. $O$ que nos pode dizer? Qual foi para si a maior alegria?}

A recuperação tanto a nível dos espaços como dos materiais e equipamentos foi uma experiência muito enriquecedora. Além da recuperação das salas do anfiteatro e do laboratório conseguimos financiamento de um projeto europeu para a recuperação do todo o espólio. Foi um trabalho difícil, mas muito apaixonante e que entusiasmou toda a equipa que comigo trabalhou. Por exemplo, a descoberta das sete camadas de tinta que cobriam as paredes do anfiteatro e que acabaram por proteger a pintura original que hoje é visível ou, ainda mais excitante, encontrar no sótão e arrecadações aparelhos e peças do século XIX que tivemos de identificar, tais como o aparelho de Carré ou o aparelho de Regnault. É difícil neste momento identificar a maior alegria pois houve ao longo do tempo vários momentos de muita alegria quando conseguíamos ultrapassar mais um dos problemas que dia a dia surgiram.

Excerto do texto sobre os "Estabelecimentos

Scientificos de Portugal: o laboratório de Chimica mineral

da Escola Polytechnica de Lisboa". Revista "O Occidente",

n. ${ }^{\circ} 434$ de 11 de janeiro de 1891, págs. 12-13.

\section{Revista "O Occidente", $n .{ }^{\circ} 434$ de 11 de janeiro de 1891}

Estabelecimentos Scientificos de Portugal: o laboratório de Chimica mineral da Escola Polytechnica de Lisboa

Ao nosso ilustre amigo, o sr. José Julio Rodrigues, lente de chimica mineral da escola polytechnica, devemos os quatro clichés que hoje publicamos... São parte de uma curiosíssima collecção de gravuras que devem, com varias plantas e alçados, figurar n'um pequeno opusculo em francez, que aquelle professor está redigindo. E' escripto no intuito de tornar conhecido no estrangeiro um estabelecimento, que hoje tanto honra este paiz, e é tão útil ao ensino da chimica, sempre fastidioso e improductivo, quando não é acompanhado de constantes e bem escolhidas demostrações experimentaes.

Quem viu há quatro anos o laboratório, a que nos referimos e o visita hoje, decerto que o não conhece; tão grandes e tão profundas foram as transformações, porque passou sob o impulso energético, insinuante e persistente, do seu actual director. Teimou e venceu; não só introduzindo de vez o ensino pratico nas cadeiras de chimica da escola polytechica, como iniciando este mesmo ensino, com intervenções que datam de longe, sem retrocessos nem esmorecimentos.

No seu conjunto, é o laboratório de chimica mineral da nossa escola polytechnica o primeiro - sem a menor duvida - da peninsula e um dos primeiros entre os estabelecimentos similares da Europa. Assim o afirmou e reconhece o celebre chimico Hofmann, em carta que reproduzimos, e assim o teem afirmado vários jornaes extrangeiros, que são, no assumpto, autoridade incontestada...

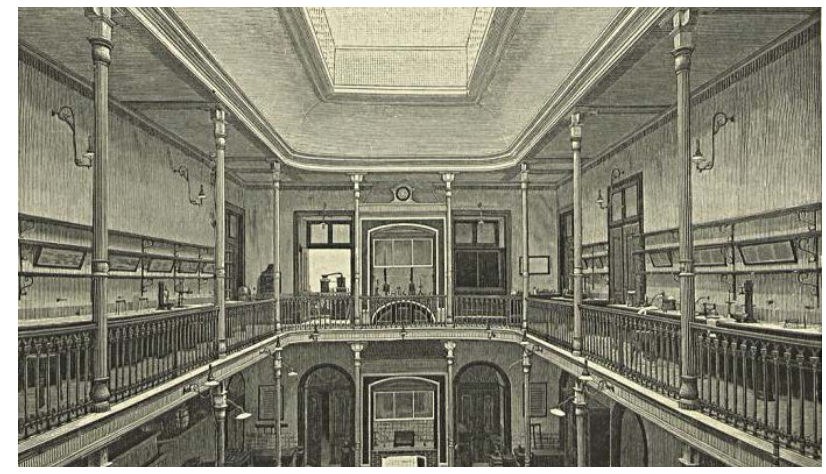

Galeria do Laboratorio de Chimica Mineral da Escola Polytechnica. Revista "0 Occidente", n. ${ }^{\circ} 434$ de 11 de janeiro de 1891, pág. 13.
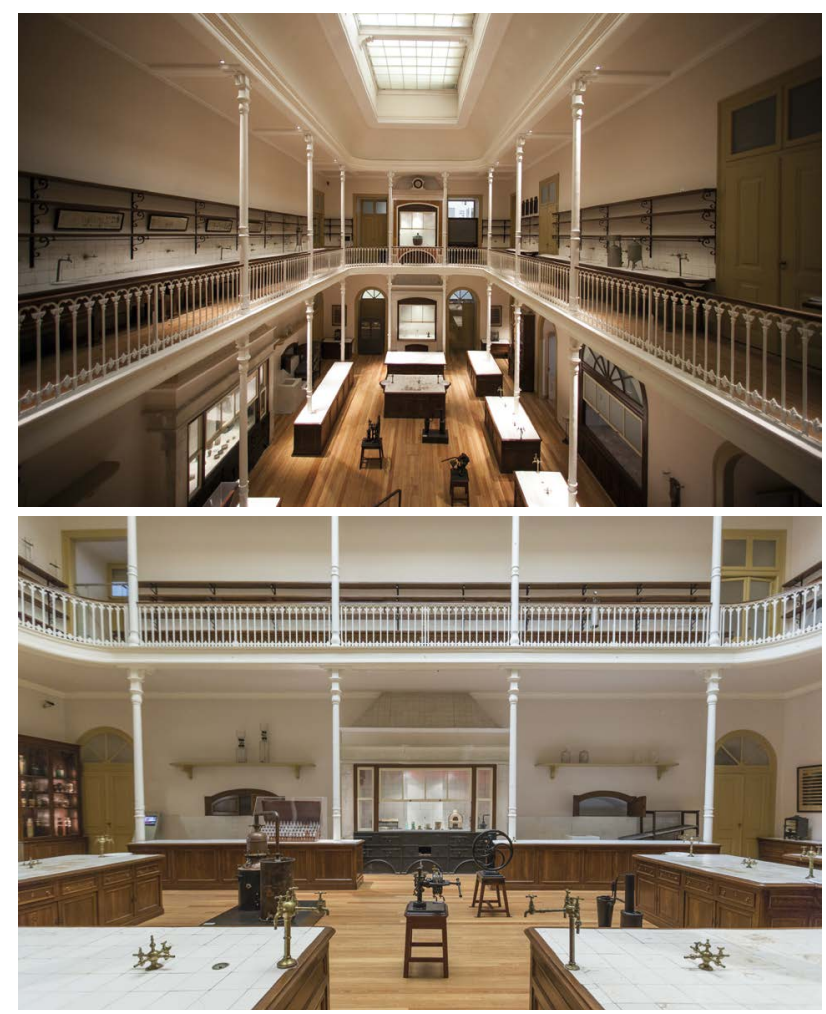

Museu Nacional de História Natural e da Ciência. Laboratório de Química da Escola Politécnica após recuperação (2003-2006). ๑ ULisboa/MUHNAC.

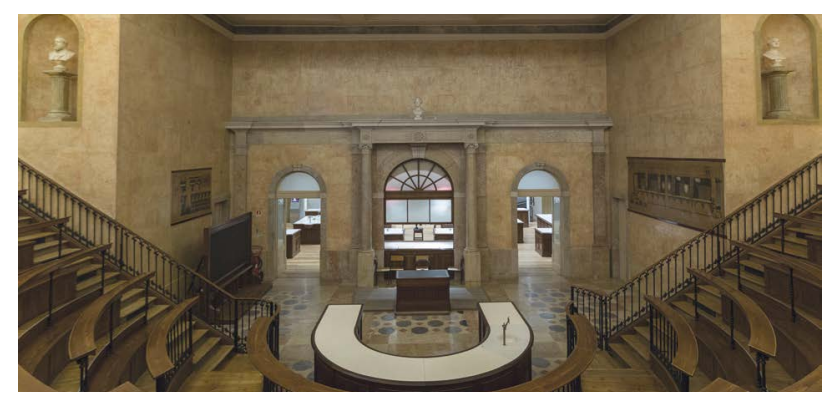

Museu Nacional de História Natural e da Ciência, Anfiteatro de Química da Escola Politécnica após recuperação (2003-2006); em conjunto com o Laboratorio Chimico foi considerado pelo químico A. W. von Hoffmann a melhor instalação de química do século XIX para o ensino e investigação. @ ULisboa/MUHNAC. 
66

O Laboratorio Chimico da Escola Politécnica é, na realidade, exemplar único do verdadeiro laboratório do século XIX.

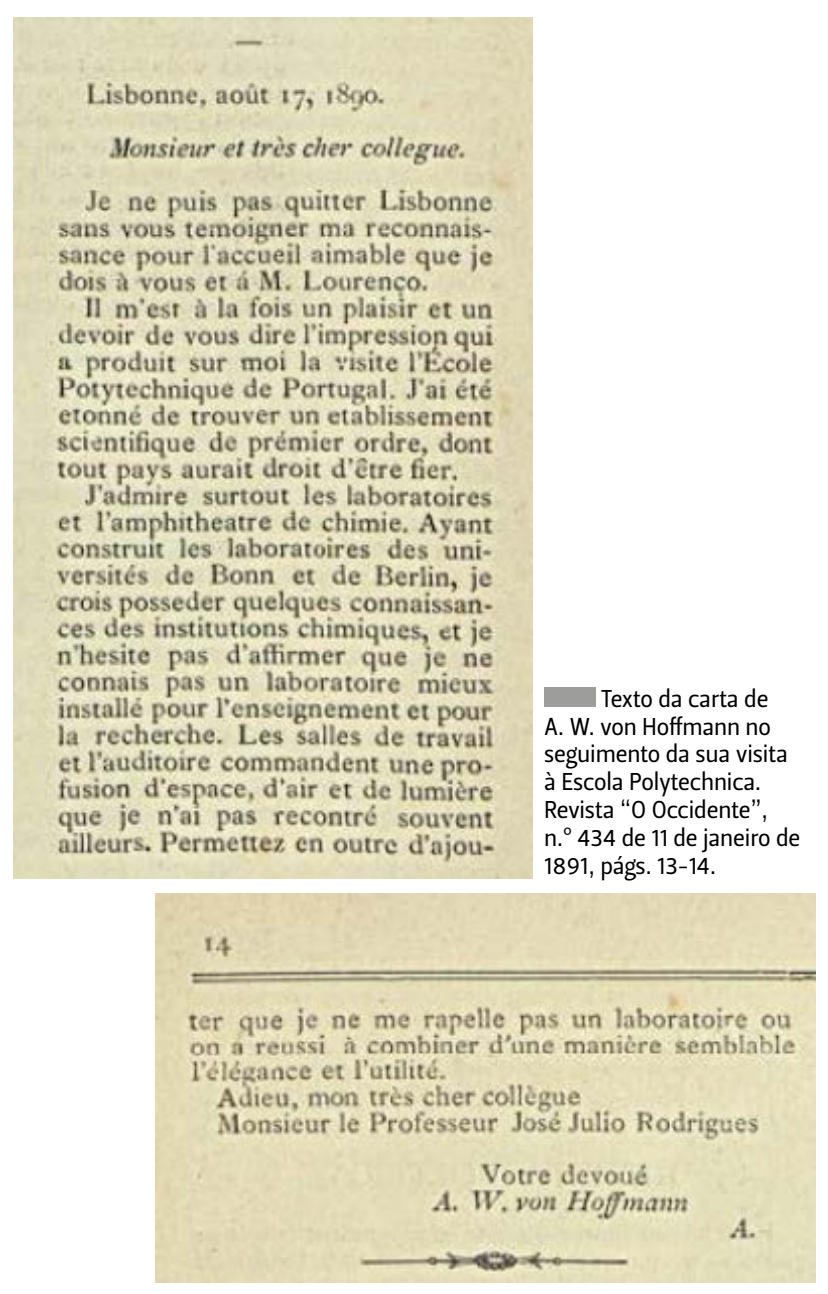

\footnotetext{
Manter a traça do museu e preservar todo o espaço sem grandes alterações estruturais deverá ser o objetivo mais alto que se pretende na recuperação de qualquer património. $\mathrm{O}$ que nos pode dizer sobre outros museus e laboratórios na Europa?

Sem dúvida que na recuperação de património a palavra-chave é preservar. De salientar a ótima colaboração que sempre encontrei nas diferentes instituições ligadas ao património e recuperação.
}

Relativamente aos outros museus e laboratórios da Europa conheço bem o Museu de LIEBIG em Giesen, na Alemanha, que corresponde ao antigo edifício de laboratório de Justus von Liebig', considerado o modelo dos laboratórios da Europa do século XIX e que visitei no decorrer dos trabalhos desta recuperação. Este laboratório foi muito danificado durante a 2. guerra mundial, mas considerando a importância que teve no século XIX e que foi pioneiro no ensino e divulgação da Química, foi reconstruído e classificado como museu. Embora com menor dimensão tem a estrutura, organização dos espaços e o conjunto Laboratório/ Anfiteatro exatamente como este nosso.

Também conheço o Museu de Ciência de Munique, centenário, sem dúvida um dos mais antigos e maiores. Possui vários edifícios cobrindo todas as áreas da ciência e tecnologia, mas relativamente à área da Química reproduz nas salas o laboratório típico do século XIX com exemplos de montagens e equipamentos da época.

Embora não conheça pessoalmente outros laboratórios europeus, segundo as informações de colegas de outros países, os laboratórios que existiam foram sendo modificados de tal modo que perderam as características iniciais. O Laboratorio Chimico da Escola Politécnica é, na realidade, exemplar único do verdadeiro laboratório do século XIX.
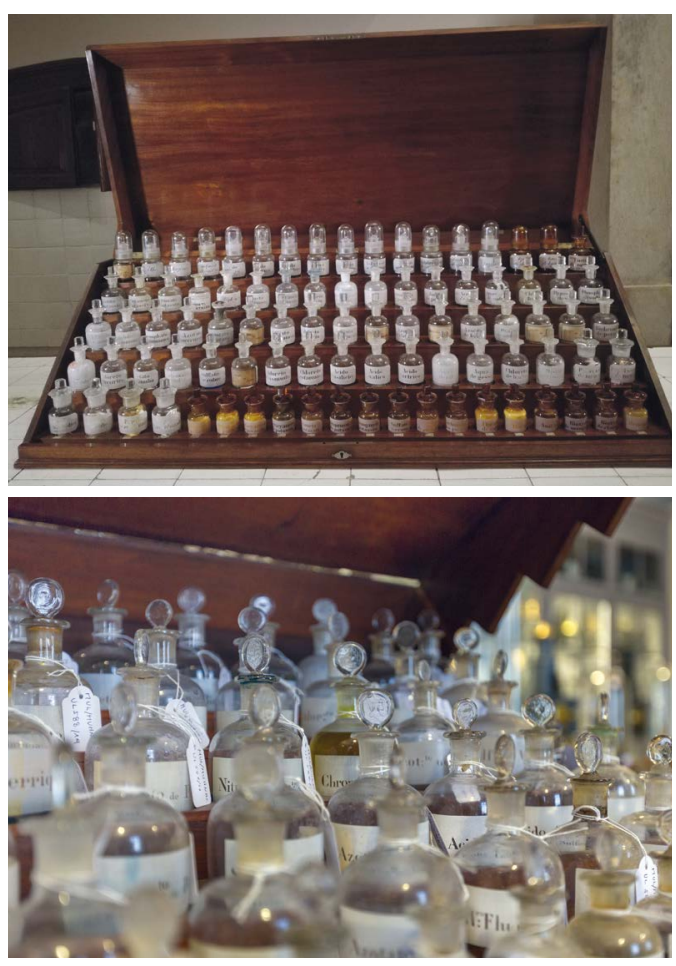

Piano de Análise; conjunto fundamental para o ensino e trabalhos de análise química no séc. XIX e início do séc. XX (imagem superior e detalhe na imagem inferior). (C) ULisboa/MUHNAC 


\section{6}

Investigar os aspetos científicos e históricos dos processos químicos e físicos da fotografia científica em Portugal, respetiva instrumentação e estudar esses resultados no contexto científico europeu da época fez-nos perceber o quão avançados e pioneiros fomos.

O que representa para si um museu?

Um museu é para mim um local de aprendizagem, reflexão e diálogo com o passado e/ou o futuro. A visita a um museu pressupõe sempre um enriquecimento. Daí a importância da escolha do percurso expositivo e da mensagem a transmitir.

Como surgiu o livro sobre 100 anos de fotografia científica no nosso país?

Existia muito material fotográfico no museu, quase perdido, e era urgentíssimo valorizar o património não catalogado. A forma mais adequada foi fazer com a minha colega Maria Estela Jardim (expert em fotografia) o projeto de investigaç̧ão intitulado Fotografia Científica que foi financiado pela FCT (PTDC/HIS-HCT/102497/2008) e que nos objetivos, para além do trabalho científico, incluía a publicação de um livro: "100 anos de fotografia científica em Portugal (1839-1939): imagens e instrumentos", livro de que muito nos orgulhamos [4]. Foi um trabalho extraordinário que viria a influenciar os alunos e os bolseiros que no âmbito do projeto fizeram o seu doutoramento, como é o caso da Isabel Marília Peres, que ainda hoje publicam nesta área. Investigar os aspetos científicos e históricos dos processos químicos e físicos da fotografia cientíica em Portugal, respetiva instrumentação e estudar esses resultados no contexto científico europeu da época fez-nos perceber o quão avançados e pioneiros fomos. É um trabalho empolgante que chega a limitar as horas de sono. Há descobertas científicas muito excitantes!

Ao longo dos anos trabalhou em várias áreas. Como retrospetiva, que trabalhos/publicações/ atividades gostava ainda de destacar?

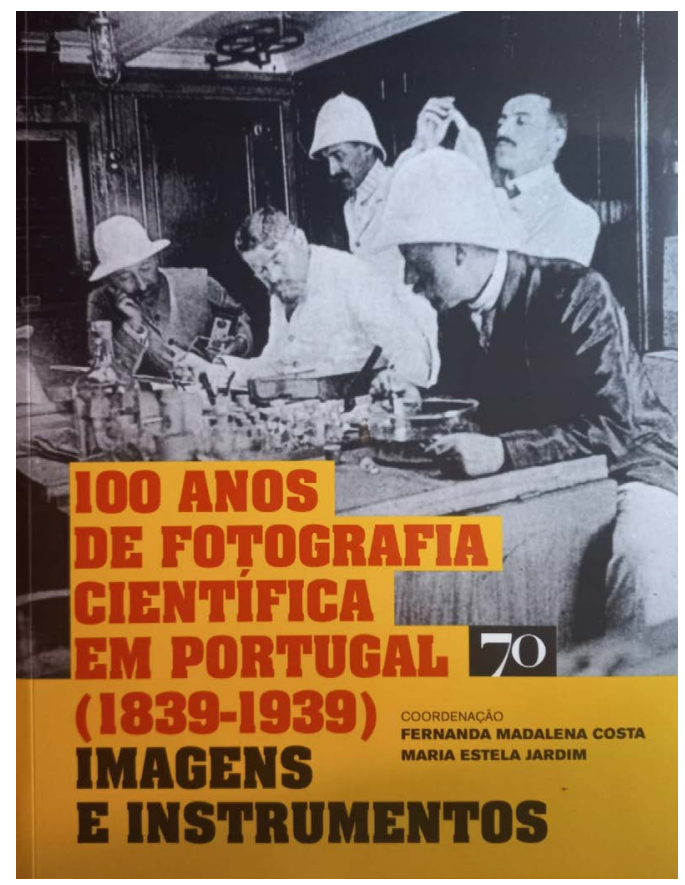

Capa do livro "100 anos de fotografia científica em Portugal (1839-1939): imagens e instrumentos".

No início da minha atividade, após o doutoramento, a criação de uma linha de investigação em química do estado sólido penso ter sido importante pois permitiu continuar parte do meu trabalho em Leeds na área da síntese de óxidos com estruturas de "perovsquite" e espinela, materiais importantes na época, e simultaneamente introduzir no ensino esta área. A obtenção de financiamento para novos equipamentos foi demorada.

Sem dúvida, a destacar todos os trabalhos de doutoramento e mestrado que orientei e os estudos que resultaram das colaborações entretanto criadas, nomeadamente com a colega Isabel Pereira da área de eletroquímica. Orientei oito alunos de doutoramento e seis de mestrado quase na totalidade na área de síntese e estudo de novos materiais e que deram origem a muitas referências e estudos internacionais posteriores.

No seguimento do meu doutoramento destacam-se os trabalhos do Manuel Rosa Nunes, da Maria de Deus Carvalho e da Amélia Lima relativamente à aplicação da técnica de Mössbauer, bem como a tese do Gilberto Pereira na área do património cultural. Mais tarde, a tese de doutoramento da Marília Peres no tema da fotografia científica.

É bom recordar como foi construído o Mössbauer: um vibrador e um detetor montados em duas barras de ferro paralelas numa parede; a fonte radioativa tinha sido adquirida ao exterior, mas a proteção da fonte foi construída pelo Manuel com chapa de chumbo! Hoje consideramos esta situação perigosa.

Em 1992 John Goodenough et al., numa publicação do Journal of Solid State Chemistry, Tin and antimony 
valence states in $\mathrm{BaSn} \mathrm{B}_{0,85} \mathrm{Sb}_{0,15} \mathrm{O}_{3-\delta}$ (J. Solid State Chem. 1992, 98, 181-186. DOI: 10.1016/0022-4596(92)900849), referem o nosso trabalho Characterization of the mixed perovskite $\mathrm{BaSn} n_{1-x} \mathrm{Sb}_{x} \mathrm{O}_{3}$ by electrolyte electroreflectance, diffuse reflectance, and $X$-ray photoelectron spectroscopy, publicado três anos antes no J. Chem. Soc., Faraday Trans. 1 (J. Chem. Soc., Faraday Trans. 1989, 85, 907-916. DOl: 10.1039/F19898500907). Foi uma alegria imensa e uma honra esta citação, situação que se mantém atualmente com este trabalho. (0 Manuel tinha sintetizado o composto $\mathrm{BaSn}_{1-x} \mathrm{Sb}_{x} \mathrm{O}_{3}$ e medido a condutibilidade elétrica com quatro elétrodos e quatro sondas de platina. Os resultados eram muito rigorosos, dando origem às várias citações conhecidas).

Também foi relevante a criação do mestrado em Química Aplicada ao Património Cultural, pioneiro em Portugal e da minha responsabilidade. Aconteceu na Faculdade de Ciências da Universidade de Lisboa em 2002 e deixou a sua marca em todo o país. Existem vários mestres e doutores que atualmente ocupam lugares de destaque no património cultural português provenientes deste mestrado. Por exemplo, o Gilberto Pereira é atualmente curador no Museu da Ciência da Universidade de Coimbra, responsável pelas Coleções de Instrumentos Científicos, tendo utilizado a técnica de Mössbauer na sua tese de mestrado [5] e feito um trabalho importante na seletividade da limpeza por LASER aplicada a objetos museológicos em ferro [6].

\section{Nas colaborações estabelecidas que países} destaca?

Sem dúvida a Inglaterra e a França e pontualmente Espanha, Alemanha e Países Baixos. Destaco frequentemente a colaboração com Grenoble e os resultados experimentais do Manuel Rosa Nunes e da Maria de Deus Carvalho que seguiram a técnica de Mössbauer.

E quem são os seus químicos de referência? Paul Hagenmuller, criador e diretor do CNRS Laboratory of Chimie du Solide em Bordéus e Anthony Roy West, professor de Electroceramics and Solid State Chemistry em Sheffield.

Durante a minha direção no MUHNAC houve uma caixa mágica que se abriu com publicações, trabalhos práticos, fotografias, relatórios técnicos nacionais e internacionais da autoria de Júlio Máximo Pimentel, José Júlio Rodrigues, Agostinho Lourenço, António Augusto de Aguiar entre outros portugueses que admiro presentemente. Temos ainda muito a divulgar sobre estes cientistas do século XIX.

Não resisti a conversar com o Manuel Rosa Nunes que destaca a sua enorme vontade para ensinar, uma grande abertura e enorme sinceridade. Quais as características que mais admira nos seus alunos?

Antes de responder a essa questão quero dizer que o Manuel era a base de tudo, suportava todos os trabalhos no laboratório com uma enorme generosidade. Apoiava muita gente, sempre com muita dedicação. Estou-Ihe muito grata. Nos meus alunos destaco o interesse intelectual em aprender, honestidade científica, alegria e paixão pelo trabalho experimental.

E no laboratório o que mais a fascina?

A geometria e a construção de fornos. Afinal é onde tudo começa!

De uma forma científica afirmamos que os alimentos são fundamentais à vida pois fornecem-nos energia, possuem funções reparadoras e de construção celular, além de protegerem e regularem o nosso corpo. As preparações dos alimentos contam histórias dos povos e de lugares. Comida também é cultura. Qual é a sua comida portuguesa favorita?

Ensopado de borrego.

E quais os livros e música que mais admira? A vida de Michael Faraday, as encíclicas papais e, de uma forma espiritual, O Nascimento de Jesus. Na minha playlist coloco Chopin, Mozart, Brahms e cantares populares portugueses.

Professora Fernanda, terminamos por aqui o seu retrato. Foi um gosto enorme aprender consigo nesta Interação Química. Combinamos uma visita guiada ao Laboratório Chimico do Museu Nacional de História Natural e da Ciência em Lisboa. Tenho a certeza que ainda tem muito para nos ensinar. Muito obrigada.

(realizado em setembro de 2021)

\section{Referências}

[1] Special Issue, $3^{\text {rd }}$ International Congress of Atomic Absortion and Atomic Fluorescence Spectrometry, Paris, pág. 125, Adam Hilger, Londres, 1971.

[2] J. B. Goodenough, "Metallic Oxides", in Progress in Solid State Chemistry, 5 145-399, H. Reiss Ed.; Pergamon Press: Oxford, Reino Unido, 1971.

[3] N. N. Greenwood e T. C. Gibb, "Mössbauer Spectroscopy", Chapman and Hall, Londres, 1971.

[4] Fernanda Madalena Costa, Maria Estela Jardim, 100 anos de fotografia científica em Portugal (1939-1939): imagens e instrumentos, Edições 70, ISBN: 978-97-2441-813-1, 2014

[5] G. Pereira, Estudo químico de técnicas de limpeza de peças museológicas em ligas de ferro. Utilização da Espectroscopia Mössbauer do ${ }^{57} \mathrm{Fe}$ na caracterização da superfície metálica, Tese de mestrado, 2006.

[6] G. Pereira, M. Pires, B. Costa, F. Costa, Laser selectivity on cleaning museologic iron artefacts, XVI International Symposium on Gas Flow, Chemical Lasers, and High-Power Lasers; Proc. SPIE-Int. Soc. Opt. Eng. 2007, 63461G. DOI: 10.1117/12.738153. 